\title{
Cost-Effectiveness of a Clinical Childhood Obesity Intervention
}

\author{
Mona Sharifi, MD, MPH, ${ }^{a}$ Calvin Franz, PhD, ${ }^{b}$ Christine M. Horan, MPH, ${ }^{c}$ Catherine M. Giles, MPH, ${ }^{d}$

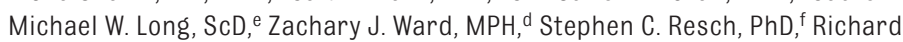 \\ Marshall, MD, ${ }^{8}$ Steven L. Gortmaker, PhD, ${ }^{d}$ Elsie M. Taveras, MD, MPHc, h
}

OBJECTIVES: To estimate the cost-effectiveness and population impact of the national implementation of the Study of Technology to Accelerate Research (STAR) intervention for childhood obesity.

METHODS: In the STAR cluster-randomized trial, 6- to 12-year-old children with obesity seen at pediatric practices with electronic health record (EHR)-based decision support for primary care providers and self-guided behavior-change support for parents had significantly smaller increases in BMI than children who received usual care. We used a microsimulation model of a national implementation of STAR from 2015 to 2025 among all pediatric primary care providers in the United States with fully functional EHRs to estimate cost, impact on obesity prevalence, and cost-effectiveness.

RESULTS: The expected population reach of a 10 -year national implementation is $\sim 2$ million children, with intervention costs of $\$ 119$ per child and $\$ 237$ per BMI unit reduced. At 10 years, assuming maintenance of effect, the intervention is expected to avert 43000 cases and 226000 life-years with obesity at a net cost of $\$ 4085$ per case and $\$ 774$ per lifeyear with obesity averted. Limiting implementation to large practices and using higher estimates of EHR adoption improved both cost-effectiveness and reach, whereas decreasing the maintenance of the intervention's effect worsened the former.

conclusions: A childhood obesity intervention with electronic decision support for clinicians and self-guided behavior-change support for parents may be more cost-effective than previous clinical interventions. Effective and efficient interventions that target children with obesity are necessary and could work in synergy with population-level prevention strategies to accelerate progress in reducing obesity prevalence.

${ }^{a}$ Department of Pediatrics, Section of General Pediatrics, Yale University School of Medicine, New Haven, Connecticut; ${ }^{b}$ Eastern Research Group Inc, Lexington, Massachusetts; ' Division of General Academic Pediatrics, Department of Pediatrics, Massachusetts General Hospital for Children, Boston, Massachusetts; Departments of ${ }^{d}$ Social and Behavioral Sciences and ${ }^{h}$ Nutrition, and ${ }^{f}$ Center for Health Decision Science, Harvard T.H. Chan School of Public Health, Harvard University, Boston, Massachusetts; ${ }^{e}$ Department of Prevention and Community Health, Milken Institute School of Public Health, George Washington University, Washington, District of Columbia; and ${ }^{g}$ Department of Pediatrics, Harvard Vanguard Medical Associates and Atrius Health Inc, Boston, Massachusetts

Dr Sharifi conceptualized and designed the study, drafted the initial manuscript, and reviewed and revised the manuscript; Dr Franz assisted with the cost analysis of the Study of Technology to Accelerate Research (STAR) trial and critically reviewed and revised the manuscript;

Ms Horan assisted with the acquisition of cost data for the STAR trial and critically reviewed the manuscript; Ms Giles and Drs Long, Resch, and Marshall contributed to the conceptualization and design of the study and critically reviewed and revised the manuscript; Mr Ward contributed to the conceptualization and design of the study, conducted the microsimulation modeling, and critically reviewed and revised the manuscript; Dr Gortmaker contributed to the conceptualization and design of the study, led the Childhood Obesity Intervention Cost-Effectiveness Study as
WHAT'S KNOWN ON THIS SUBJECT: Excess health care costs attributable to obesity demand effective and efficient strategies. To facilitate appropriate resource allocation, economic evaluations can aid explicit assessments of intervention efficiency and allow for comparisons between interventions. Such analyses are lacking in pediatric obesity management.

WHAT THIS STUDY ADDS: A childhood obesity intervention involving electronic decision support in primary care improved BMl at a cost of $\$ 119$ per child and $\$ 237$ per BMl unit reduced. National implementation over 10 years could reach $>2$ million children and avert 43000 obesity cases

To cite: Sharifi M, Franz C, Horan CM, et al. Cost-Effectiveness of a Clinical Childhood Obesity Intervention. Pediatrics 2017; 140(5):e20162998 
TABLE 1 Components of the STAR Intervention, Including Point-of-Care Electronic Decision Support for Clinicians and Self-Guided Behavior-Change Support for Parents

\begin{tabular}{|c|c|}
\hline $\begin{array}{l}\text { Intervention } \\
\text { Components }\end{array}$ & Details \\
\hline \multirow[t]{17}{*}{ EHR modifications } & Best Practice Advisory in the Epic EHR \\
\hline & $\begin{array}{l}\text { Alerts pediatrician of } \mathrm{BMI} \geq 95 \text { th percentile when height and weight are } \\
\text { measured and documented into the EHR for children ages 6-12 y }\end{array}$ \\
\hline & Includes links to the following: \\
\hline & $\begin{array}{l}\text { 1. A prepopulated SmartSet order entry and note template (see below for } \\
\text { details) }\end{array}$ \\
\hline & 2. Centers for Disease Control and Prevention growth charts \\
\hline & $\begin{array}{l}\text { 3. Evidence-based childhood obesity screening and management guidelines }{ }^{2,} \\
4\end{array}$ \\
\hline & 4. The STAR study Web site, which housed: \\
\hline & Printable patient-education handouts on obesity-related behavior change \\
\hline & A list of local weight management programs \\
\hline & $\begin{array}{l}\text { Searchable database of local physical activity programs near a given } \\
\text { address }\end{array}$ \\
\hline & Training materials on the EHR tools and how to use them \\
\hline & $\begin{array}{l}\text { Additional resources to aid clinicians during follow-up obesity visits (an } \\
\text { outline for how to structure visits) }\end{array}$ \\
\hline & $\begin{array}{l}\text { SmartSet well child visit order entry and note template specific for obesity that } \\
\text { facilitates: }\end{array}$ \\
\hline & $\begin{array}{l}\text { Documentation and coding of BMI percentile categories and nutrition and } \\
\text { physical activity counseling (to comply with HEDIS recommendations) as wel } \\
\text { as obesity and obesity-related comorbidities }\end{array}$ \\
\hline & $\begin{array}{l}\text { Referrals to weight management programs, nutritionists, or subspecialty } \\
\text { clinics (eg cardiology and endocrinology) }\end{array}$ \\
\hline & Orders for obesity-related screening laboratory tests, if appropriate \\
\hline & $\begin{array}{l}\text { Text on healthy behaviors for inclusion in the after-visit summary routinely } \\
\text { provided to families }\end{array}$ \\
\hline \multirow[t]{2}{*}{ Clinician training } & $\begin{array}{l}\text { On-site presentations to pediatric practices to demonstrate EHR modifications } \\
\text { and resources }\end{array}$ \\
\hline & $\begin{array}{l}\text { Biweekly performance feedback e-mails regarding adherence to HEDIS } \\
\text { performance measures }\end{array}$ \\
\hline \multirow{2}{*}{$\begin{array}{l}\text { Materials for } \\
\text { families }\end{array}$} & Posters displayed in pediatric practices promoting health behavior change \\
\hline & $\begin{array}{l}\text { Materials mailed to families quarterly, including } 4 \text { newsletters and } 4 \text { magazines } \\
\text { about healthy eating }\end{array}$ \\
\hline
\end{tabular}

HEDIS, Healthcare Effectiveness Data and Information Set.

Clinical interventions to manage childhood obesity have the potential to reduce the prevalence of obesity in adults, improve long-term quality of life, and reduce health care costs. ${ }^{1}$ Both a 2010 report of the US Preventive Service Task Force $^{2}$ and a Cochrane review ${ }^{3}$ concluded that comprehensive, highintensity behavioral interventions for childhood obesity, compared with usual pediatric clinical care, could reduce the prevalence of overweight among children. However, the adoption of expert recommendations ${ }^{4}$ and nationally standardized performance measures ${ }^{5}$ for childhood obesity management in pediatric primary care has been limited. ${ }^{6-8}$ Clinicians face competing demands for screening and prevention that exceed what they can feasibly manage within the limits of well-child care. ${ }^{9-12}$

The use of electronic health records (EHRs) has increased rapidly over the last half-decade, likely fueled by federal financial incentives. ${ }^{13,14}$ EHR functionality can be leveraged to facilitate childhood obesity management by prompting diagnosis and providing decision support and electronic resources for evaluation, management, and follow-up care. In the recent Study of Technology to Accelerate Research (STAR) clinical trial, 6- to 12-year-old children with obesity had a smaller increase in BMI after 1 year, compared with usual care, when seen at pediatric primary care practices randomly assigned to an intervention that included electronic clinical decision support (CDS) for pediatricians and selfguided behavior-change support for parents. ${ }^{15,16}$

Clinicians, administrators, and policy makers face increasing demands on time and resources to achieve a broad range of child health goals. Economic evaluations of proven interventions empower decisionmakers with the information needed to prioritize interventions that provide the best value to patients and the health system. To date, there are few such analyses of interventions to manage children with obesity in clinical settings. A recent systematic review of primary care-based interventions for childhood obesity calls into question their value in producing clinically meaningful outcomes and highlights the importance of examining financial costs from both the individual and societal perspectives. ${ }^{17}$ In this study, we examined the costs associated with the STAR clinical childhood obesity intervention with the following 2 goals: (1) to inform clinicians and policy makers about what investment would be required to adopt this intervention in other pediatric primary care settings, and (2) to evaluate the costeffectiveness and population impact of the intervention if implemented nationally.

\section{METHODS}

\section{Intervention and Effect Estimate}

The modeled intervention was based on the STAR cluster-randomized clinical trial conducted from 2010 to 2013 at Harvard Vanguard Medical Associates and Atrius Health Inc, a multisite group practice in eastern Massachusetts. ${ }^{15,16}$ Intention-to-treat analyses demonstrated a smaller increase in BMI over 1 year among 194 children ages 6 to 12 years 
TABLE 2 Population Reach, Cost, and Effectiveness Results From a 10-Year Microsimulation Model of the National Implementation of the STAR Clinical Childhood Obesity Intervention, 2015-2025

\begin{tabular}{lcc}
\hline Population Reach & Mean & $95 \%$ UI \\
\hline 10-y reach, millions & 2.0 & 1.8 to 2.2 \\
First-year reach, millions & 0.6 & 0.5 to 0.6 \\
Intervention effect & & \\
$\quad$ 1-y BMI change & -0.5 & -0.9 to -0.1 \\
Intervention costs & & \\
$\quad$ 10-y total cost, \$ (millions) & 239 & 186 to 292 \\
$\quad$ Annual costs, \$ (millions) & 24 & 19 to 29 \\
$\quad$ Cost per child & 119 & 94 to 145 \\
10-y totals (2015-2025) & & \\
Years with obesity averted, thousands & 226.0 & 56.6 to 323.7 \\
$\quad$ Obesity costs averted, \$ (millions) & 64 & 16 to 92 \\
$\quad$ Net costs difference, \$ (millions) & 175 & 105 to 263 \\
$\quad$ Health care costs saved per dollar invested, \$ & 0.27 & 0.06 to 0.45 \\
2025 projected obesity prevalence & & \\
$\quad$ Overall obesity prevalence reduction, \% & 0.01 & 0.00 to 0.02 \\
$\quad$ Cases of obesity averted, thousands & 42.8 & 9.8 to 63.9 \\
$\quad$ Child obesity prevalence reduction, \% & 0.05 & 0.01 to 0.08 \\
$\quad$ Cases of child obesity averted, thousands & 37.9 & 9.0 to 55.5 \\
Cost-effectiveness ratios, \$ & & \\
$\quad$ Intervention cost per BMl unit reduction per child & 237 & 106 to 1276 \\
$\quad$ Net cost per year with obesity averted & 774 & 327 to 3763 \\
$\quad$ Net cost per case of obesity averted & 4085 & 1691 to 20550 \\
\hline
\end{tabular}

Costs are in 2014 dollars and discounted at $3 \%$ per year.

a Incremental cost-effectiveness ratios comparing the intervention with usual care.

TABLE 3 Projected Component Costs for the STAR Intervention Implemented Nationally Among Pediatric PCPs With Fully Functional EHRs, 2015-2025

\begin{tabular}{|c|c|c|c|}
\hline Intervention Costs & $\begin{array}{c}\text { 10-y Total Costs, } \$ \\
\text { (Millions): } \\
\text { Mean ( } 95 \% \text { UI) }\end{array}$ & $\begin{array}{l}\text { Per Child Costs, \$: Mean } \\
\qquad(95 \% \text { UI) }\end{array}$ & $\begin{array}{l}\text { Percent of } \\
\text { Total Costs }\end{array}$ \\
\hline Total cost & 239.0 (185.7 to 292.3) & 119.4 (94.13 to 145.18$)$ & 100 \\
\hline Start-up costs & $9.7^{\mathrm{a}}$ & 4.84 (4.47 to 5.29$)$ & 4.1 \\
\hline EHR modifications & $2.7^{\mathrm{a}}$ & $1.33(1.22$ to 1.45$)$ & 1.1 \\
\hline Web site development & $5.3^{\mathrm{a}}$ & 2.65 (2.45 to 2.90$)$ & 2.2 \\
\hline PCP training & $0.5^{\mathrm{a}}$ & $0.27(0.25$ to 0.30$)$ & 0.2 \\
\hline Material development & $1.2^{\mathrm{a}}$ & 0.59 (0.55 to 0.65$)$ & 0.5 \\
\hline Ongoing costs & $229.3(176.0$ to 282.6$)$ & 114.56 (89.19 to 140.26$)$ & 95.9 \\
\hline $\begin{array}{l}\text { PCP training, } \\
\text { performance feedback }\end{array}$ & $3.5^{\mathrm{a}}$ & 1.75 (1.62 to 1.91$)$ & 1.5 \\
\hline Web site maintenance & $9.4^{\mathrm{a}}$ & $4.72(4.36$ to 5.16$)$ & 4.0 \\
\hline $\begin{array}{l}\text { Additional PCP time per } \\
\text { child }\end{array}$ & $30.6(-8.5$ to 64.5$)$ & $15.31(-4.42$ to 32.61$)$ & 12.8 \\
\hline Mailings to families & $185.7(152.3$ to 216.5$)$ & $92.78(77.54$ to 106.80$)$ & 77.7 \\
\hline
\end{tabular}

${ }^{a}$ Based on deterministic estimates from the STAR trial and dissemination.

with $\mathrm{BMI} \geq 95$ th percentile seen at the 5 practices randomly assigned to the intervention $(-0.51[95 \%$ confidence interval, -0.91 to -0.11$]$ ) compared with 184 children seen at the 4 practices randomly assigned to usual care, adjusted for clustering by practice site and for patient and parent demographic characteristics.

The intervention involved EHR-based CDS and training for pediatricians at the point of care to promote recognition and recommended management of obesity among 6- to 12-year-old children during pediatric well-child care. Parents also received materials by mail 4 times during the 1-year intervention to support selfguided health behavior change for their children. The EHR modifications included diagnosis and screening prompts and decision support for obesity management using the
EpicCare ambulatory EHR software (Epic Systems, Verona, WI). Table 1 summarizes the intervention's components, which are reported in detail elsewhere. ${ }^{15,16}$

\section{Modeling Framework}

The Childhood Obesity Intervention Cost-Effectiveness Study (CHOICES) has been described in detail previously. ${ }^{18}$ In brief, this modeling framework builds on the Australian Assessing Cost-Effectiveness intervention ${ }^{19,20}$ in obesity ${ }^{21}$ and prevention $^{22}$ methodologies to evaluate the national implementation of childhood obesity interventions in the United States through a rigorous, stakeholder-informed process. The CHOICES microsimulation model is a stochastic, discrete-time, individuallevel model programmed in Java that simulates an open cohort of the US population from 2015 to 2025 . The model estimates the costeffectiveness of obesity interventions through their impact on BMI, obesity prevalence, and obesity-related health care costs over the 10-year simulation ending in 2025 and following guidelines of the first US Panel on Cost-Effectiveness in Health and Medicine. ${ }^{23}$ We report cost per unit change in BMI, per case of obesity averted, and per year with obesity averted as the primary measures of cost-effectiveness. Additional details about the model, including the logic pathway linking the STAR intervention to change in obesity-related outcomes and health care costs (as well as the model parameters), are provided in the Supplemental Information.

\section{Population Reach}

The target population for the intervention scaled to the national level is all children in the United States ages 6 to 12 years with a BMI $\geq 95$ th percentile seen by pediatric primary care providers (PCPs) who have "fully functional" EHRs $^{24,25}$ capable of the type of 


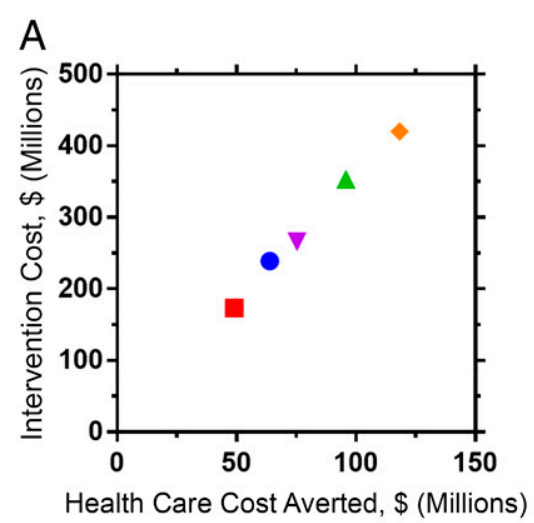

(2015-2025)

B

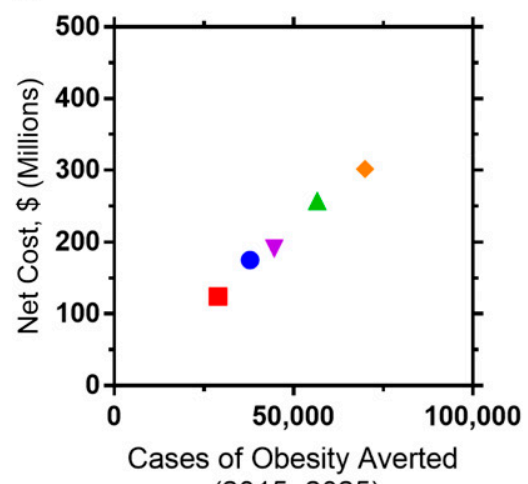

(2015-2025)
- National implementation (base case)

- Implementation at large practices only

\ Extrapolated EHR adoption in 2015

Large practices only

$\boldsymbol{\nabla}$ + extrapolated EHR adoption in 2015 (increase over base case)

Large practices only

- + 2014 HHS goal for EHR adoption (increase over base case)

\section{C}

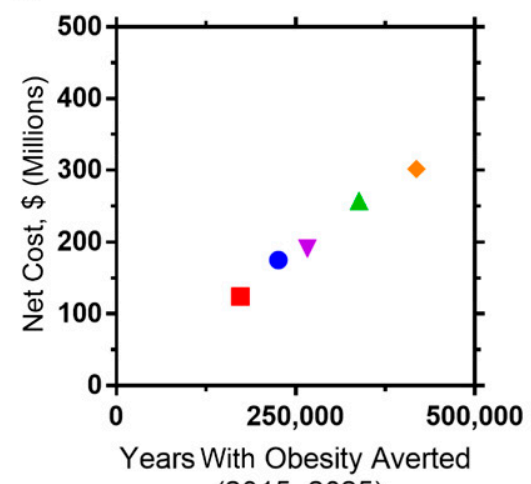

(2015-2025)

FIGURE 1

Cost-effectiveness planes showing the mean intervention costs and effectiveness estimates from 10-year microsimulation models of the STAR clinical childhood obesity intervention, with varying scenarios of national implementation by practice type and by using different estimates for EHR adoption (2015-2025). HHS, Health and Human Services. All metrics are reported for the population over a 10-year period (2015-2025) and discounted at 3\% per year.

decision-support tools used in STAR. Supplemental Figure 3 displays a hierarchical representation of the intervention's target population. Because the effect estimate used to calculate health benefits was based on intention-to-treat analyses from the STAR trial, we assumed that the total number of children reached by the intervention (the intent-to-treat population) and who received a health benefit from the intervention (the benefiting population) were equal. We further assumed that all pediatric PCP groups with fully functional EHRs would implement the intervention with high fidelity and that the intervention effects on one-year BMI change observed in the STAR trial would be reproducible in other pediatric primary care settings.
To calculate the target population and the intervention's potential reach (Supplemental Table 4), we first approximated the proportion of all US children ages 6 to 12 years (per 2010 US census estimates) seen for well-child care by pediatric PCPs with fully functional EHRs. To do this, we collected published estimates of the number of pediatric PCPs in the United States ${ }^{26}$ with fully functional EHRs in various practice settings (eg, solo or 2-provider practices, multispecialty group or health maintenance organization practices, etc) ${ }^{25}$ and the average number of children ages 6 to 12 years old seen by pediatric PCPs in each of these practice settings. ${ }^{27}$ We used this proportion in the microsimulation to estimate the intervention's reach among US children with a BMI $\geq 95$ th percentile. $^{18}$

\section{Measuring Costs}

To estimate costs associated with national implementation, we followed standard guidelines ${ }^{28-31}$ and adopted a modified societal perspective, which includes direct medical costs and nonmedical costs (such as postage for mailings, refreshments for physician trainings, etc) but excludes the opportunity cost of time spent by families making lifestyle changes. See Supplemental Table 4 for details of the cost analysis. Cost calculations were in 2014 dollars, adjusted for inflation by using the US Bureau of Labor Statistics Consumer Price Index, and discounted at $3 \%$ per year. We assessed 1-time, start-up intervention costs of modifications to the EHR, Web site development, PCP training, and the development of materials for selfguided behavior-change support for parents; we treated start-up costs as capital costs annualized over a 10-year period. We used cost data from the dissemination of STAR to another practice setting to conservatively estimate the programming costs associated with the EHR modifications. We calculated ongoing costs of continued training and performance feedback to PCPs, Web site maintenance, additional clinical time spent by the PCPs per child, and mailings to parents. We did not observe differences in the frequency of follow-up visits, clinical referrals, or laboratory orders between the intervention and usualcare children during the yearlong trial (E.M.T., unpublished data). We scaled estimated intervention costs to the national level on the basis of whether costs were incurred (1) per child, (2) per PCP, (3) per group of pediatric PCPs sharing a fully functional EHR system, and (4) per PCP practice sharing a physical location (see Supplemental 
Table 4 for details). Finally, health care cost savings because of the intervention were modeled over the 10-year simulation period based on associations between obesity and health care costs from national data, as previously detailed. ${ }^{18,32}$

\section{Uncertainty and Sensitivity Analyses}

We conducted probabilistic uncertainty analyses by simultaneously sampling parameter values from predetermined distributions. We report mean values and 95\% uncertainty intervals (UIs) using Monte Carlo simulations over 1000 iterations of the model for a population of 1 million individuals scaled to the national population size. In addition to the probabilistic sensitivity analysis, we evaluated the impact of varying the model's assumptions.

\section{Varying Implementation Based on Practice Size}

To examine potential economies of scale, we conducted a scenario analysis limiting the implementation of the intervention to large practices only, ie, multispecialty group practices and medical school-and hospital-based clinics. These large practices likely have more information technology infrastructure and established relationships with their EHR vendors, which would potentially diminish the costs of making modifications to their EHRs. To estimate information technology programming costs in these scenarios for the EHR modifications, we used direct cost estimates from the STAR trial conducted in a multispecialty group practice with a well-established EHR.

\section{Varying Estimates of EHR Adoption Among PCPS}

In the base case, we modeled the impact of the intervention among PCPs with fully functional EHRs using conservative estimates of EHR adoption based on a 2012 survey of pediatricians, as detailed in Supplemental Table $4 .{ }^{25}$ To account for the likely continued uptake of EHRs from 2012 to our simulation period of 2015 to 2025 , we considered 2 additional scenarios with higher estimates of EHR adoption (Supplemental Table 4). In the first, we assumed the pace of increase in EHR adoption per year observed from 2009 (range $3.5 \%-14.5 \%$ ) to 2012 (range $3.3 \%$ $30.1 \%)^{25}$ continued through 2015 (range 3.3\%-45.7\%). We applied these estimates to model national implementation among all practices and then among large practices only. Next, we modeled a more ambitious scenario, assuming $65 \%$ fully functional EHR adoption among PCPs at large practices in 2015 based on the fiscal year 2014 target for EHR adoption among office-based PCPs defined by the US Department of Health and Human Services. ${ }^{33}$

Varying Maintenance of the Intervention's Effect

Finally, given uncertainty around our assumption of effect maintenance, we examined the impact of the linear decay of the intervention effect over various time frames $(10$, 7,5 , and 3 years), in which weight gradually reverts back to the baseline trajectory over the specified time period.

\section{RESULTS}

The national implementation of a clinical childhood obesity intervention with EHR-based CDS for clinicians and self-guided behaviorchange support for families from 2015 to 2025 would affect $>6000$ pediatricians with fully functional EHRs who provide care to $10.5 \%$ of the 24.6 million children ages 6 to 12 years in the total US population.

Table 2 displays the results of the microsimulation. Over 10 years, the intervention would reach $\sim 2$ million (95\% UI, 1.8 million to 2.2 million) children with obesity and would cost \$239 million (95\% UI, $\$ 186$ million to $\$ 292$ million), or \$119 (95\% UI, \$94 to \$145) per child reached (Table 2). Relative to usual care, the intervention could reduce mean per capita BMI by $0.5 \mathrm{U}$ (95\% UI, 0.1 to 0.9 ) among those reached, with an estimated intervention cost of $\$ 237$ (95\% UI, \$106 to \$1276) per BMI unit reduced. Over 10 years, the BMI reductions would avert $\sim \$ 64$ million in health care costs $(95 \%$ UI, $\$ 16$ million to $\$ 92$ million), partially offsetting the intervention cost and resulting in a 10-year net cost of \$175 million (95\% UI, \$105 million to $\$ 263$ million). At 10 years, assuming the BMI reductions during the intervention persist, the intervention would avert 42900 (95\% UI, 9800 to 63900 ) cases of obesity and 226000 (95\% UI, 56600 to 323700 ) lifeyears with obesity at a net cost of $\$ 4085$ per case $(95 \%$ UI, $\$ 1691$ to $\$ 20550$ ) and $\$ 774$ per year (95\% UI, $\$ 327$ to $\$ 3763$ ) with obesity averted.

Table 3 shows the total, start-up, and ongoing costs of the intervention in detail. The majority of the intervention costs are attributable to the mailings of newsletters and magazines to families (78\%) and additional time spent by PCPs during clinical visits (13\%).

Figure 1 displays the results of the scenario analyses (detailed results shown in Supplemental Table 5). Limiting the implementation of the intervention to large practices, including multispecialty group practices and medical school-and hospital-based clinics, reduced the projected population reach by $25 \%$ to 1.5 million (95\% UI, 1.4 million to 1.7 million) children but also reduced the net cost of the intervention by $29 \%$ to $\$ 124$ million (95\% UI, \$71 million to $\$ 191$ million). Increasing the estimates of fully functional EHR adoption among pediatricians expanded the intervention reach and, in turn, population health benefits. If federal goals for EHR adoption ${ }^{33}$ were achieved among pediatric PCPs, 
the intervention could reach 3.7 million children (95\% UI, 3.4 million to 4 million), even if limited to large practice settings, and potentially avert 79200 (95\% UI, 20000 to 114900) cases of obesity.

Finally, Supplemental Fig 4 shows the cost-effectiveness outcomes (cost per case of obesity averted and cost per year with obesity averted) when we vary our assumption regarding how long the intervention's effect is maintained. We observed an inverse, linear relationship between the duration of effect maintenance and the cost-effectiveness estimates. For example, the cost per year with obesity averted changes from $\$ 774$ (95\% UI, \$327 to \$3763) in the base case to $\$ 3543$ (95\% UI, $\$ 2214$ to $\$ 11154$ ) assuming 3-year maintenance of effect.

\section{DISCUSSION}

The national implementation of the STAR clinical childhood obesity intervention over 10 years could reach a projected 2 million 6 - to 12-year-old children with obesity. Intervention costs were $\sim \$ 119$ per child and $\$ 237$ per unit change in BMI under our baseline assumptions for national implementation. At 10 years, assuming maintenance of the intervention effect, the intervention could avert 43000 cases of obesity and $>226000$ life-years with obesity. Limiting the implementation to large practice settings with potential economies of scale improved measures of cost-effectiveness, and higher national EHR adoption would increase population reach up to 3.7 million children. More conservative estimates around the maintenance of the intervention's effect worsened cost-effectiveness projections.

The per-child incremental cost of the modeled STAR intervention compared with usual care ranged from $\$ 113$ to $\$ 119$ depending on the implementation scenario considered (ie, implementation at large practice settings only versus all pediatric primary care practices with fully functional EHRs). These per-child costs are lower than the $\$ 196$ per-child incremental cost (2011 US dollars) reported in the only previous US study that examined the cost of a primary care-based intervention for childhood obesity among preschool-aged children, a trial that did not demonstrate a significant effect on BMI. ${ }^{34}$ Notably, this previous cost analysis did not include the costs of clinician training but did include estimates of family time and out-of-pocket costs because the intervention involved additional, study-specific visits (unlike STAR). Another US study of family-based group treatment of parents and 8- to 12-year-old children with overweight or obesity estimated that the intervention cost $\$ 1448$ per family and $\$ 209.17$ per percent reduction in BMI percentile over the 95th percentile (currency year not reported). ${ }^{35}$ The lack of comparable strategies to estimate both costs and outcomes makes comparisons between studies difficult, especially because many studies are from outside the United States. Yet, among the cost-effectiveness analyses of primary care-based interventions that have been conducted in other countries, the adjusted mean difference in BMI of the STAR was greater in magnitude than those reported for these other studies, ${ }^{36-38}$ and the per-child cost of STAR appears to be lower. ${ }^{34}$

Supplemental Table 6 compares STAR with 13 other childhood obesity interventions using the CHOICES microsimulation model. Projected reductions in childhood obesity prevalence are more substantial with cost-saving, population-level strategies than clinical interventions. For example, the cost per BMI unit change for sugar-sweetened beverage taxes (\$2.49), the elimination of tax subsidies for advertising unhealthy food to children $(\$ 0.66)$, and nutrition standards for all other food and beverages sold in schools (\$6.10) are much less than for bariatric surgery (\$1600). ${ }^{18,39}$ Preventing obesity among children requires relatively small changes in energy balance, an average reduction of $64 \mathrm{kcal}$ per day in the youth daily energy gap would meet Healthy People 2020 goals. ${ }^{40-42}$ However, far more substantial energy deficits are necessary to reduce BMI among children who already have obesity. The projected impact of the STAR intervention on the prevalence of obesity is high and intervention costs are low when compared with other clinical interventions, such as bariatric surgery. ${ }^{18}$

Our examination of intervention costs revealed that direct mailings to families would account for $78 \%$ of the costs associated with national implementation. Newer approaches using remote and mobile technologies, such as patient portals and text messaging, might substantially lower ongoing costs and allow for dissemination of tailored materials that may further improve outcomes. ${ }^{43,44}$ Additional time spent by PCPs during clinical visits with each child accounted for $\sim 13 \%$ of total costs. These costs were based on our conservative, stakeholder-informed estimates and not on actual data from time studies with clinicians. It is feasible that improved integration of CDS tools into clinician workflows could reduce these time costs and further improve cost-effectiveness.

Despite rapid increases in EHR adoption nationally, most of the development, research, and funding of EHR-based CDS has been focused on adult patients, and well-developed features tailored to pediatric settings have lagged behind. ${ }^{45}$ Although office-based pediatricians report rates of EHR adoption comparable 
to estimates for all office-based physicians (79\% with any EHR in 2012), only $1 \%$ of pediatricians reported having fully functional EHRs with pediatric-supportive features ("weight-based medication dosing, tracking recommended well-child visits and immunizations, calculating catch-up immunizations, and plotting growth charts and computing BMI"). ${ }^{25}$ In response, federal standards were released in 2013 to encourage the development of pediatric-supportive EHR features with plans to include them in future criteria for meaningful use incentives. ${ }^{46}$ Our sensitivity analyses demonstrate greater population reach with higher rates of fully functional EHR adoption, and the integration of pediatric-supportive features into existing EHR platforms will likely further reduce the costs associated with implementation.

This study has several limitations. First, the effect and cost estimates used in our model are based on a single study and subject to the study's limitations. Although STAR was a cluster-randomized trial with objective growth measures that ensured high-quality and reliable results, residual confounding could remain, and results may not generalize to uninsured and lowerincome populations in different geographic regions. To address the uncertainty around the effect estimate, we conducted probabilistic sensitivity analyses, and to improve the generalizability of our estimates of cost, we used national data to estimate labor and material costs, if available. Second, the model carries the base case assumption that the intervention effects on 1-year weight changes that are observed in the STAR trial will be (1) maintained and stable beyond 1 year and (2) reproducible in other pediatric primary care settings. Given the lack of longterm follow-up of clinician practice and child BMI to support the first assumption, we present sensitivity analyses with varying maintenance of the intervention's effect. For the second, implementation success at other practice settings will certainly be modified by the unique features of the patient population, clinicians, and the practice overall, such as regional variations in care delivery and obesity prevalence. However, continued training and performance feedback efforts included in our implementation scenario may support long-term fidelity of the intervention. Lastly, our base case model uses 2012 data on EHR adoption among pediatric practices. ${ }^{25}$ To address the likely higher uptake in 2015 (the start of the model's simulation period), we conducted scenario analyses with higher levels of adoption.

We did not consider intervention impact beyond the 10-year simulations nor the potential collateral benefits, or ripple effects, ${ }^{47}$ from changes in weight or health behaviors among families of children involved in the intervention. We also did not consider the impact of behaviors promoted by the intervention (improved nutrition, activity, and sleep) on health outcomes other than weight trajectories. The results may overestimate the cost of implementation because we assumed that each health system would implement the intervention independently and create materials and resources de novo when, in fact, resources developed for the STAR study are available for dissemination. Therefore, the projected benefits may be an underestimation, and true costs may be lower.

\section{CONCLUSIONS}

Implementing electronic decisionsupport tools to facilitate obesity management in pediatric primary care may be a more cost-effective strategy than previous clinical interventions, although it may be less cost-effective than policies such as taxes and school-based interventions. High-quality and efficient clinical interventions that target children at high risk who already have obesity are necessary and could work in synergy with population-level, primary prevention strategies to accelerate progress in reducing the prevalence of childhood obesity.

\section{ABBREVIATIONS \\ CDS: clinical decision support CHOICES: Childhood Obesity Intervention Cost- Effectiveness Study \\ EHR: electronic health record PCP: primary care provider STAR: Study of Technology to Accelerate Research \\ UI: uncertainty interval}

principal investigator, and critically reviewed and revised the manuscript; Dr Taveras conceptualized and designed the STAR trial as principal investigator and critically reviewed and revised the manuscript; and all authors have made substantial contributions to conception and design, acquisition of data, or analysis and interpretation of data; drafted the article or revised it critically for important intellectual content; and approved the final manuscript as submitted.

This trial has been registered at www.clinicaltrials.gov (identifier NCT01537510).

Dol: https://doi.org/10.1542/peds.2016-2998

Accepted for publication Aug 2, 2017

Address correspondence to Mona Sharifi, MD, MPH, Department of Pediatrics, Section of General Pediatrics, Yale University School of Medicine, 333 Cedar St, PO Box 208064, New Haven, CT 06520-8064. E-mail: mona.sharifi@yale.edu 
PEDIATRICS (ISSN Numbers: Print, 0031-4005; Online, 1098-4275).

Copyright (C) 2017 by the American Academy of Pediatrics

FINANCIAL DISCLOSURE: The authors have indicated they have no financial relationships relevant to this article to disclose.

FUNDING: The Study of Technology to Accelerate Research was supported by the American Recovery and Reinvestment Act of 2009 (R18AE000026). The Childhood Obesity Intervention Cost-Effectiveness Study was supported in part by grants from The JPB Foundation, the Robert Wood Johnson Foundation (grant 66284), and the Centers for Disease Control and Prevention (grant U48/DP001946), including the Nutrition and Obesity Policy Research and Evaluation Network. Dr Sharifi was supported by grants (K12 HS 022986 and K08 HS024332) from the Agency for Healthcare Research and Quality. Dr Taveras was supported by a National Institutes of Health (NIH) grant (K24 DK10589) from the National Institute of Diabetes and Digestive and Kidney Diseases. This work is solely the responsibility of the authors and does not represent the official views of the Centers for Disease Control and Prevention or any of the other funders. Funded by the National Institutes of Health $(\mathrm{NIH})$.

POTENTIAL CONFLICT OF INTEREST: The authors have indicated they have no potential conflicts of interest to disclose.

\section{REFERENCES}

1. World Health Organization. Report of the first meeting of the ad hoc working group on science and evidence for ending childhood obesity; June 18-20, 2014; Geneva, Switzerland. Available at: http://www.who.int/end-childhoodobesity/echo-final-report-august-2014. pdf. Accessed July 25, 2017

2. Barton M; US Preventive Services Task Force. Screening for obesity in children and adolescents: US Preventive Services Task Force recommendation statement. Pediatrics. 2010;125(2):361-367

3. Oude Luttikhuis H, Baur L, Jansen $H$, et al. Interventions for treating obesity in children. Cochrane Database Syst Rev. 2009;(1):CD001872

4. Spear BA, Barlow SE, Ervin C, et al. Recommendations for treatment of child and adolescent overweight and obesity. Pediatrics. 2007;120(suppl 4):S254-S288

5. National Committee for Quality Assurance. Weight Assessment and Counseling for Nutrition and Physical Activity for Children/Adolescents; Healthcare Effectiveness Data and Information Set (HEDIS) measures. Available at: https://www.ncqa.org/ Portals/0/Weight Assessment and Counseling.pdf. Accessed September 13, 2017

6. Huang TT, Borowski LA, Liu B, et al. Pediatricians' and family physicians' weight-related care of children in the U.S. Am J Prev Med. 2011;41(1):24-32

7. Perrin EM, Skinner AC, Steiner MJ. Parental recall of doctor communication of weight status: national trends from 1999 through 2008. Arch Pediatr Adolesc Med. 2012;166(4):317-322
8. Sharifi M, Rifas-Shiman SL, Marshall R, et al. Evaluating the implementation of expert committee recommendations for obesity assessment. Clin Pediatr (Phila). 2013;52(2):131-138

9. Schor EL. Rethinking well-child care. Pediatrics. 2004;114(1):210-216

10. Belamarich PF, Gandica R, Stein RE, Racine AD. Drowning in a sea of advice: pediatricians and American Academy of Pediatrics policy statements. Pediatrics. 2006;118(4). Available at: www.pediatrics. org/cgi/content/full/118/4/e964

11. Mangione-Smith R, DeCristofaro $\mathrm{AH}$, Setodji CM, et al. The quality of ambulatory care delivered to children in the United States. N Engl J Med. 2007;357(15):1515-1523

12. Norlin C, Crawford MA, Bell CT, Sheng $X$, Stein MT. Delivery of well-child care: a look inside the door. Acad Pediatr. 2011;11(1):18-26

13. Blumenthal D. Stimulating the adoption of health information technology. N Engl J Med. 2009;360(15):1477-1479

14. Blumenthal D. Launching HITECH. N Engl J Med. 2010;362(5):382-385

15. Taveras EM, Marshall R, Horan CM, et al. Rationale and design of the STAR randomized controlled trial to accelerate adoption of childhood obesity comparative effectiveness research. Contemp Clin Trials. 2013;34(1):101-108

16. Taveras EM, Marshall R, Kleinman $K P$, et al. Comparative effectiveness of childhood obesity interventions in pediatric primary care: a clusterrandomized clinical trial. JAMA Pediatr. 2015;169(6):535-542

17. Sim LA, Lebow J, Wang Z, Koball A, Murad MH. Brief primary care obesity interventions: a meta-analysis Pediatrics. 2016;138(4):e20160149

18. Gortmaker SL, Wang YC, Long MW, et al. Three interventions that reduce childhood obesity are projected to save more than they cost to implement. Health Aff (Millwood). 2015;34(11):1932-1939

19. Carter R, Vos T, Moodie M, Haby M, Magnus A, Mihalopoulos C. Priority setting in health: origins, description and application of the Australian Assessing Cost-Effectiveness initiative. Expert Rev Pharmacoecon Outcomes Res. 2008;8(6):593-617

20. Carter R, Moodie M, Markwick A, et al. Assessing cost-effectiveness in obesity (ACE-obesity): an overview of the ACE approach, economic methods and cost results. BMC Public Health. 2009;9:419

21. Haby MM, Vos T, Carter R, et al. A new approach to assessing the health benefit from obesity interventions in children and adolescents: the assessing cost-effectiveness in obesity project. Int J Obes. 2006;30(10):1463-1475

22. Vos T, Carter R, Barendregt J, et al. Assessing Cost-Effectiveness in Prevention (ACE-Prevention): Final Report. Melbourne, Australia: University of Queensland, Brisbane and Deakin University; 2010

23. Siegel JE, Weinstein MC, Russell LB, Gold MR; Panel on CostEffectiveness in Health and Medicine. Recommendations for reporting cost-effectiveness analyses. JAMA. 1996;276(16):1339-1341

24. Hsiao CJ, Hing E, Ashman J. Trends in electronic health record system use among office-based physicians: United 
States, 2007-2012. Natl Health Stat Rep. 2014; (75):1-18

25. Lehmann CU, O'Connor KG, Shorte VA, Johnson TD. Use of electronic health record systems by office-based pediatricians. Pediatrics. 2015;135(1). Available at: www.pediatrics.org/cgi/ content/full/135/1/e7

26. Agency for Healthcare Research and Quality. The number of practicing primary care physicians in the United States: primary care workforce facts and stats no. 1. 2014. Available at: www.ahrq.gov/research/findings/ factsheets/primary/pcwork1/index. html. Accessed August 7, 2015

27. Bocian AB, Wasserman RC, Slora EJ, Kessel D, Miller RS. Size and age-sex distribution of pediatric practice: a study from Pediatric Research in Office Settings. Arch Pediatr Adolesc Med. 1999;153(1):9-14

28. Russell LB, Gold MR, Siegel JE, Daniels $\mathrm{N}$, Weinstein MC; Panel on CostEffectiveness in Health and Medicine. The role of cost-effectiveness analysis in health and medicine. JAMA. 1996;276(14):1172-1177

29. Weinstein MC, Siegel JE, Gold MR, Kamlet MS, Russell LB. Recommendations of the panel on costeffectiveness in health and medicine. JAMA. 1996;276(15):1253-1258

30. Gold MR, Siegel JE, Russell LB, Weinstein MC. Cost-Effectiveness in Health and Medicine. Oxford, United Kingdom: Oxford University Press; 1996

31. Drummond M, O'Brien B, Stoddart G, Torrance G. Methods for the Economic Evaluation of Health Care Programmes. 2nd ed. 0xford, United Kingdom: Oxford University Press; 1997

32. Finkelstein EA, Trogdon JG. Public health interventions for addressing childhood overweight: analysis of the business case. Am J Public Health. 2008;98(3):411-415

33. U.S. Department of Health and Human Services. Annual performance plan and report, fiscal year 2016. 2015. Available at: www.hhs.gov/about/ budget/performance/goal-1-objectivef/index.html. Accessed September 11, 2015

34. Wright DR, Taveras EM, Gillman MW, et al. The cost of a primary carebased childhood obesity prevention intervention. BMC Health Serv Res. 2014; $14: 44$

35. Epstein LH, Paluch RA, Wrotniak BH, et al. Cost-effectiveness of family-based group treatment for child and parental obesity. Child Obes. 2014;10(2):114-121

36. McCallum Z, Wake M, Gerner B, et al. Outcome data from the LEAP (Live, Eat and Play) trial: a randomized controlled trial of a primary care intervention for childhood overweight/mild obesity. Int J Obes. 2007;31(4):630-636

37. Wake M, Baur LA, Gerner B, et al. Outcomes and costs of primary care surveillance and intervention for overweight or obese children: the LEAP 2 randomised controlled trial. BMJ. 2009;339:b3308

38. Wake M, Lycett K, Clifford SA, et al. Shared care obesity management in 3-10 year old children: 12 month outcomes of HopSCOTCH randomised trial. BMJ. 2013;346:f3092

39. Cradock AL, Barrett JL, Kenney EL, et al. Using cost-effectiveness analysis to prioritize policy and programmatic approaches to physical activity promotion and obesity prevention in childhood. Prev Med. 2017;95(suppl):S17-S27

40. Hall KD, Butte NF, Swinburn BA, Chow CC. Dynamics of childhood growth and obesity: development and validation of a quantitative mathematical model. Lancet Diabetes Endocrinol. 2013;1(2):97-105

41. Hall KD, Sacks G, Chandramohan D, et al. Quantification of the effect of energy imbalance on bodyweight. Lancet. 2011;378(9793):826-837

42. Wang YC, Orleans CT, Gortmaker SL. Reaching the healthy people goals for reducing childhood obesity: closing the energy gap. Am J Prev Med. 2012;42(5):437-444

43. Sharifi M, Dryden EM, Horan CM, et al. Leveraging text messaging and mobile technology to support pediatric obesity-related behavior change: a qualitative study using parent focus groups and interviews. J Med Internet Res. 2013;15(12):e272

44. Taveras EM, Marshall R, Sharifi M, et al. Connect for health: design of a clinical-community childhood obesity intervention testing best practices of positive outliers. Contemp Clin Trials. 2015;45 (pt B):287-295

45. Conway PH, White PJ, Clancy C. The public role in promoting child health information technology. Pediatrics. 2009;123(suppl 2) :S125-S127

46. Agency for Healthcare Research and Quality (AHRQ). New children's electronic health record format announced. 2013. Available at: https://archive.ahrq.gov/news/ newsletters/research-activities/ 13mar/0313RA43.html. Accessed January 15, 2015

47. Gorin AA, Wing RR, Fava JL, et al; Look AHEAD Home Environment Research Group. Weight loss treatment influences untreated spouses and the home environment: evidence of a ripple effect. Int J Obes. 2008;32(11):1678-1684 